has described in some detail the occurrence of amphogenic and monogenic (both arrhenogenic and thelygenic) females in another terrestrial isopod, Trichoniscus provisorius Racovitza. The apparently normal $3: 1$ segregation for colour in this brood would not be expected if this brood were a parthenogenetic one such as are known to occur in triploid Trichoniscus elisabethce Herold (Vandel ${ }^{3}$ ).

The 'exceptional' male in Brood 1 of 1938 was of the black type with a pattern of yellow markings (var. variegatus Lereb., see Collinge ${ }^{4}$ ). Such a variety appears, from collections and also from observations on the segregations in amphogenic broods, to be normally a sex-limited character found only in females. Most males are entirely black in colour (var. plumbeus Lereb., see Collinge ${ }^{4}$. All the red and black females in this brood also had the pattern of yellow markings.

Work on the genetics of the different varieties of this woodlice is being continued, and it is also proposed to investigate the genetics of the amphogenic and monogenic types of females. Such work must be slow since only one brood per year is obtained.

\author{
School of Agriculture, \\ Cambridge. \\ Nov. 14. \\ ${ }^{1}$ Collinge, $J$. Zool. Res., 3, 101 (1918). \\ 'Vandel, Bull. biol., 72, 147 (1938). \\ ${ }^{3}$ Vandel, Bull. biol., 68, 418 (1934). \\ ‘ Collinge, J. Zool. Res., 3, 31 (1918).
}

\section{Mechanism of Magnetization}

ACcording to the classical theory of magnetization, if a long solenoid is excited with direct current so as to produce a magnetic force $H$ along the axis, then if a long steel rod is placed axially in the solenoid, the magnetizing force at the central part of the rod will be $H$ and will be uniform over the cross-section of the rod. The following experimental results, how. ever, indicate that this conception is incorrect.
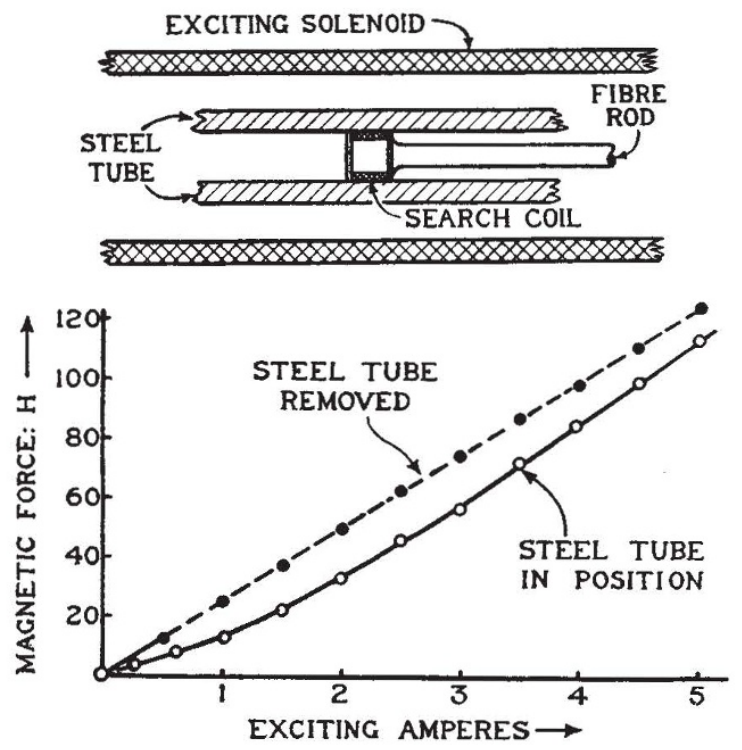

A solid-drawn steel tube 24 in. long, $\frac{3}{4}$ in. outside diameter and $\frac{3}{8}$ in. inside diameter was arranged axially and centrally in a magnetizing solenoid about $4 \mathrm{ft} .9 \mathrm{in}$. long and about $4 \frac{1}{2} \mathrm{in}$. internal diameter. A search coil wound on a fibre rod support was arranged inside the steel tube midway between the two ends, the general arrangement being as shown in the diagram. The magnetic force inside the tube was then measured ballistically and the results are shown by the full-line curve, which has been plotted as a function of the exciting current of the solenoid. The steel tube was then removed whilst the search coil remained in position centrally in the solenoid. The magnetic force was then measured ballistically, and the values so obtained are shown by the broken straight line in the graph.

It appears therefore that, for a given excitation, the magnetic force $H$ inside the tube may be only about one half the value which is obtained when the steel tube is removed.

These investigations are being extended by using a nest of tubes arranged with an annular space between every two consecutive tubes so that the magnetic force may be measured in each of the annular spaces.

$$
\text { T. F. WALL. }
$$

Department of Electrical Engineering, University, Sheffield. Nov. 14.

\section{Friction of Clean Metals and the Influence of Surface Films}

WHEN a metal is cleaned in air, the surface will still be covered with a relatively thick layer of oxide and other adsorbed impurities. Friction measurements are usually made with metals coated in this way, and if a lubricant is added, it is superimposed on the surface films already present. Recent experiments ${ }^{1}$ show that an intermittent clutching and breaking away of the surfaces takes place during sliding. The results suggest that local adhesions may occur at the points of metallic contact, and that the sliding friction may be due to the making and breaking of these welded junctions. The molecular field of force at the surface of a solid is profoundly modified by the presence of an adsorbed layer, so that, if this view is correct, we should expect the surface film to have a large influence on the friction.

It is a matter of considerable experimental difficulty to remove the last traces of adsorbed film from a metal surface, and few attempts to measure the kinetic friction of naked metals have been made. $\mathrm{Jacob}^{2}$, and Shaw and Leavey ${ }^{3}$ found that when metal surfaces were partially cleaned in a vacuum the static friction showed an increase. Holm and Kirschstein ${ }^{4}$ showed that the adhesion between metals which had been heated in a vacuum was high. On the other hand, Pöschl ${ }^{5}$ states that when surfaces are cleaned in a good vacuum the sliding friction between the surfaces becomes vanishingly small. We have measured the kinetic friction between various metal surfaces which have been cleaned by prolonged heating, in a high vacuum, to a temperature near the volatilization point. Within the limits of experimental accuracy, the friction was independent of the sliding speed, and in every case the removal of the surface films caused a very large increase in the friction. The coefficient of kinetic friction between outgassed nickel and tungsten surfaces, for example, was $\mu=6$, which is nearly twenty times greater than the friction of these metals when 'cleaned' in the ordinary way.

These observations lend strong support to the view that local adhesion between metals may occur. Under normal conditions, when the metals are exposed to the air, the presence of adsorbed films will reduce 